\title{
O ensino de língua e a formação docente na perspectiva da pesquisadora Glaís Sales Cordeiro: uma brasileira em Genebra
}

\author{
Language teaching and teacher training from Glaís Sales Cordeiro's standpoint: a Brazilian in Geneve
}

L'enseignement de langue et la formation d'enseignant sur la perspective de la chercheur Glaís Sales Cordeiro: une brésilienne à Genève

\section{Entrevista por Cleide Inês Wittke}

Universidade Federal de Pelotas - UFPEL - Pelotas - Rio Grande do Sul - Brasil

\section{Introdução}

Por ocasião da realização de meus estudos de pós-doutorado na Universidade de Genebra (UNIGE), mais especificamente na Faculdade de Psicologia e de Ciências da Educação (FPSE), com bolsa do governo brasileiro, via CAPES, diversas atividades foram efetuadas no campo de pesquisa e de ensino em Genebra, dentre as quais se inclui este diálogo com a professora Dra. Glaís Sales Cordeiro, uma brasileira que trabalha há mais de 10 anos na UNIGE. O tema das questões centra-se no processo de ensino de língua e de formação desse docente. Cordeiro é membro do GRAFE (Groupe de recherche pour l'analyse du français enseigné), grande grupo de pesquisa da FPSE, subdividido em projetos específicos direcionados a entender os processos do ensino da leitura, da escrita, da oralidade, da literatura, bem como da formação e da ação docente.

Ao longo de sua carreira como professora e pesquisadora, Glaís Sales Cordeiro tem dedicado seus estudos da linguagem a investigar sobre os processos que constituem o ensino e a aprendizagem das línguas (portuguesa e francesa), na modalidade falada e escrita. Além disso, a pesquisadora também tem como foco refletir sobre a formação dos professores de francês, investigando tanto o objeto ensinado quanto a ação desses profissionais no ensino obrigatório (ou fundamental, como dizemos no Brasil). No momento, suas pesquisas direcionam-se ao ensino e à aprendizagem da compreensão de textos orais e escritos nos anos iniciais de escolarização. Dentre suas diversas publicações, destacamos sua colaboração no livro La lecture enseignée au fil de l'école obrigatoire. L'exemple genevois, publicado em 2014; o artigo Justifications des élèves et médiation de l'enseignante dans une tâche de compréhension en lecture d'un conte en maternelle, publicado em 2014, na revista Repères; e também a tradução do livro (juntamente com Roxane Rojo) "Gêneros orais e escritos na escola", de Bernard Schneuwly e Joaquim Dolz, publicado em 2004, no Brasil. 
CW - Os Parâmetros Curriculares Nacionais $(1998,1999)$ orientam que o ensino de língua portuguesa deve ser trabalhado a partir de atividades voltadas à leitura, à produção oral e escrita e à gramática. Desde então, muitos estudiosos, tais como Geraldi (2006), Rojo (2002), Travaglia (2003, 2004), Antunes (2009), Koch e Elias (2010), citando apenas alguns deles, abordam o tema. No entanto, muitos professores ainda ensinam a língua portuguesa por meio de exercícios fragmentados, com foco específico na metalinguagem. Os pesquisadores genebrinos realizaram e continuam realizando vários estudos nesse campo, portanto, seria interessante que você falasse sobre o modo como a gramática é ensinada nas escolas de Genebra. E também, sob quais perspectivas teóricas e práticas os futuros professores de línguas vêm sendo formados na UNIGE?

GSC - Nossa equipe faz uma distinção entre gramática textual e gramática da frase, e, sob esse ponto de vista, há dois eixos no ensino da gramática. Pela própria tradição do ensino de língua materna (ou primeira, com se diz aqui em Genebra), na Suíça francófona existem dois grandes objetivos que fundamentam o ensino na escola primária. O primeiro diz respeito à compreensão e à produção de textos orais e escritos, enquanto que o segundo remete ao funcionamento da língua. No segundo eixo, temos o ensino de gramática, ortografia, vocabulário e conjugação. Entendemos ser necessário que haja um estudo da gramática como um domínio em si, e um estudo da gramática em uso no texto oral e/ou escrito. Mas cabe ressaltar que há grande diferença entre a gramática oral e a gramática no texto escrito.

Ao estabelecer um paralelo com o ensino de português, eu consigo entender o que aconteceu nas escolas brasileiras, mas meu olhar é mais crítico, pois, em um dado momento, o ensino de língua saiu de uma postura extremamente normativa com relação à gramática, já que ensinar português era ensinar gramática e ortografia (vocabulário também) para outro extremo, sem qualquer referência à nomenclatura. Saiu da postura normativa e foi para outro posicionamento completamente oposto, que é o de ensinar, sobretudo, a produção de textos e assim a gramática passou a ser ensinada somente no âmbito do texto e não no da frase.

E o que vejo hoje, no Brasil, pois ministro cursos de formação em algumas universidades e tenho contato também com professores do ensino fundamental e médio, é uma ausência quase total do ensino de gramática na sala de aula. Isso acontece porque a gramática está completamente diluída no ensino de produção textual e no ensino de leitura, e vai chegar um momento, talvez eu esteja exagerando, em que os alunos não vão conhecer mais as noções gramaticais, eles não vão saber o que é um advérbio, um adjetivo, o que é uma oração coordenada ou uma oração subordinada. Essa realidade mostra que ainda estamos no extremo e não encontramos o equilíbrio entre esses dois grandes objetivos do ensino de língua materna. No meu entender, e do GRAFE, esses dois eixos, produção/compreensão de textos e funcionamento da língua (gramática, ortografia, etc.) devem constituir os pilares do ensino de língua, pelos menos no nível do ensino fundamental.

Ao analisar os livros didáticos voltados ao ensino de português, podemos ver que as atividades gramaticais e também lexicais estão tão diluídas no ensino da leitura e da produção textual que, muitas vezes, acabam passando despercebidas. Sob esse enfoque, não se objetiva mais um ensino - que também é necessário - da gramática por si mesma. Em contrapartida, aqui em Genebra, procuramos formar os nossos futuros professores para o ensino de produção oral e escrita, de leitura, mas também para o ensino do léxico, da ortografia e da gramática.

Desse modo, na formação inicial e continuada de professores de francês, buscamos mostrar como abordar esses objetos, estabelecendo relação entre atividades que você chamou de descontextualizadas, e que eu entendo como uma atividade de análise da língua. Nós, professores formadores, partimos de uma situação 
complexa que é o texto, em produção ou compreensão, e depois propomos atividades descontextualizadas, mas que mantêm uma relação com o texto de base. Esse trabalho é feito para que as noções gramaticais sejam incorporadas e que, de fato, os alunos as estudem, porque também é função da escola trabalhar tais conhecimentos, para voltar depois, eventualmente, ao texto e poder reutilizar essas noções de modo prático. Em resumo, podemos dizer que há um eixo da gramática em uso e outro das noções gramaticais, dos conceitos a serem apreendidos.

Por exemplo, os alunos devem ser levados a tomar consciência de como se processa a subordinação e também a coordenação de duas orações e/ou frases. É fundamental que entendam quais são os efeitos que essa coordenação ou subordinação de frases vai criar no leitor. Isso é outra questão, mas se faz necessário que o aluno entenda em que consistem esses fenômenos para que possa empregá-los de maneira consciente na produção de um texto ou compreender, em leitura, por que um autor os utiliza em seu dizer. Os dois processos devem ocorrer em paralelo e precisam ser trabalhados em sala de aula.

No ensino de Genebra, essa questão ficou mais simples, pois, até há pouco tempo, os professores chamavam de Francês I às atividades que correspondem à compreensão e produção de textos, e de Francês II, às atividades que dizem respeito a tudo que é relacionado com o estudo do funcionamento da língua. Assim, os dois objetivos são bem distintos tanto para os professores quanto para os alunos, já que ambos sabem o que estão fazendo em cada um dos dois momentos, no processo de ensino e de aprendizagem de francês. O Francês I e o Francês II são duas disciplinas diferentes. Por exemplo, o professor pode iniciar sua aula fazendo um trabalho a partir da retomada de uma produção textual já realizada, digamos, do ponto de vista dos elementos de textualização, como os organizadores textuais ou a coesão verbal e, depois, à tarde, ele aborda questões gramaticais, pois ensina o que é um grupo nominal, bem como quais são suas funções na língua.

No que tange às referências teóricas subjacentes ao tratamento e ao ensino da gramática no cantão de Genebra (região romanda), essas provêm da gramática distributiva e da gerativa transformacional. Nesse sentido, os processos de manipulação, substituição e supressão dos constituintes da frase são bastante importantes para o ensino e a aprendizagem da gramática de frases.

CW- A partir dos anos 2000, teve início um movimento voltado para trabalhar a língua com base nos gêneros textuais usados nas mais diversas instâncias discursivas, principalmente após a publicação do livro "Gêneros orais e escritos na escola", de Schneuwly e Dolz, que você traduziu juntamente com Roxane Rojo, em 2004. Minha questão é: Como inserir de modo sistemático o ensino dos gêneros textuais e das sequências didáticas tanto na formação dos professores de línguas como em cursos de formação continuada voltados a profissionais em serviço? Como se dá esse processo na formação dos professores de Genebra? Quais são os resultados obtidos com as pesquisas que investigam sobre o ensino dos gêneros textuais na sala de aula?

GSC- Acredito que esta pergunta poderá ser melhor respondida pelo professor Joaquim Dolz ${ }^{1}$, pois, como no momento suas pesquisas estão focadas na ação do professor em sala de aula, certamente, ele terá dados mais precisos sobre esse tema.

No que se refere à questão de como inserir de maneira sistemática o ensino dos gêneros de texto e das sequências didáticas na formação dos professores de língua, penso que esse ensino deveria constar nas

\footnotetext{
1 Joaquim Dolz é professor ordinário na Didática das Línguas da FPSE e coordena três pesquisas, sendo duas delas direcionadas à formação e à ação docente. Uma intitula-se Les gestes didactiques des enseignants face aux obstacles d'apprentissage d'un genre argumentatif e a outra Objets et processus de la formation en didactique du français. Analyse de la formation des enseignants du primaire e du secondaire en production écrite.
} 
ementas das disciplinas. Acredito que a noção de gênero textual deveria funcionar como ponto de partida e de chegada, sendo bem definida, já que a sequência didática é apenas um dispositivo de ensino.

Penso, então, que o currículo deveria, no caso da disciplina de língua, começar pela explicitação do gênero textual. E na sequência (é claro que estou partindo da visão de nossa equipe), penso que os textos escolhidos e traduzidos no livro editado em 2004 possibilitam caracterizar precisamente as dimensões constitutivas de um gênero textual. E essa caracterização terá como base os agrupamentos de gêneros que lá foram propostos, em termos das ordens do narrar, do relatar, do argumentar, etc., os quais permitem justamente entender e definir melhor cada família de gêneros.

No entanto, existe um problema fundamental na formação de base e também na formação continuada do professor, a saber: Com quais gêneros a gente pode exemplificar os diferentes agrupamentos? A dificuldade que vejo no contexto brasileiro é que existe uma vontade muito grande de trabalhar com gêneros da atualidade, ou principalmente com as novas tecnologias. No início de 2015, quando estive em um evento no Brasil, os professores fizeram muitas perguntas sobre as novas tecnologias e acerca de nossos trabalhos relacionados a esse tema. Dentre as dúvidas dos professores estava a indagação se uma página da web é ou não considerada como um gênero. Esclareci que tudo depende daquilo que se encontra na referida página. É preciso analisar cada página da web, ou cada site, pois, dependendo da página, é possível encontrar inúmeros gêneros nela.

Sim, essa questão é bastante complexa e a escolha feita por nossa equipe, tendo como objetivo dar uma formação pela qual o professor consiga trabalhar com o gênero em sala de aula, foi a de estudar gêneros que têm características mais definidas (canônicas) e que apresentam poucas variações. Tomamos essa decisão porque, dessa forma, você consegue mostrar para o professor, e também para o aluno, quais são as dimensões que constituem e definem um gênero, ou seja, conteúdo temático, plano do texto, elementos de textualização. A partir dessa abordagem do gênero textual, fica mais fácil introduzir e depois dar continuidade a esse trabalho na progressão curricular, percorrendo todo o ensino fundamental e chegando até o ensino médio.

Esses são alguns nortes sobre o ensino de francês e também sobre a formação docente em Genebra. Na formação de base dos professores, temos duas disciplinas de didática do Francês, I e II, em dois anos diferentes da formação. No primeiro ano, os futuros professores são preparados para a etapa de apresentação da situação de comunicação. Os acadêmicos escolhem um gênero com o qual querem trabalhar e discutem com o professor titular que vai recebê-los na escola. Depois, os futuros professores realizam duas semanas de atividades denominadas "tempo de terreno" (temps de terrain).

Como o primeiro ano de formação em Ciências da Educação é básico, somente no segundo ano os licenciandos são selecionados para o tempo de terreno. Essa seleção é feita com base nos resultados dos exames, também no nível de língua inglesa e alemã e de uma prova de francês, envolvendo compreensão e produção de textos. É então no segundo ano que iniciam as disciplinas mais voltadas à formação do professor, mais ligadas à prática propriamente dita, havendo, nessa fase, o temps de terrain. Já os estágios com total responsabilidade pela aula ocorrem no terceiro ano da formação específica, havendo apenas um estágio curto no segundo ano.

Na disciplina de Didática do Francês I, nas duas primeiras semanas, os acadêmicos observam as aulas de um professor titular, conferindo como ele ensina a produção escrita. Se os futuros professores não conseguiram ver em detalhes tudo o que o professor pode fazer em relação à produção escrita, eles são orientados a complementar suas informações fazendo uma entrevista com esse profissional. Depois, os estudantes voltam para a universidade para terem aula conosco.

Feito isso, os futuros professores retornam, após duas ou três semanas, para o trabalho no terrain e é nesse momento que eles vão fazer a apresentação da situação de comunicação aos alunos e levá-los a realizar a produção inicial dos textos do gênero escolhido. Para o trabalho de avaliação do curso, os 
licenciandos analisam os aspectos que funcionaram ou não nos textos produzidos pelos alunos, podendo assim tomar consciência dessa complexidade, juntamente com a turma.

Em Didática do Francês II, no terceiro ano de formação, os futuros professores têm novamente três a quatro aulas e duas semanas de temps de terrain. Depois, mais duas semanas de aula com a gente e, novamente, duas semanas de temps de terrain. Nas primeiras duas semanas, como já fizeram no ano anterior uma apresentação de uma situação de comunicação e uma produção inicial, nós os preparamos menos para essa atividade. A escolha do gênero é feita juntamente com o professor titular que os recebe. O quadro muda, já que não é uma continuidade do trabalho realizado no ano anterior. Na formação, tudo é feito para que os estudantes trabalhem sempre em séries diferentes e com diversos professores titulares, com vistas a também compreender melhor a noção de progressão curricular.

Nessa etapa, surge um novo elemento na formação, pois é preciso levar em conta os objetivos da escola, os quais nortearão os módulos de aprendizagem a serem produzidos e aplicados nas duas últimas semanas de temps de terrain. Nesse momento, os licenciandos analisam as produções dos alunos e, com base nos textos investigados, são orientados a produzir um módulo de atividades de escrita para ser aplicado em duas semanas. Além disso, devem analisar essas produções do ponto de vista da ortografia e elaborar um módulo voltado ao ensino desse objeto, separado do módulo direcionado à produção escrita. Nosso objetivo é separar o trabalho com esses dois objetos de ensino. Todavia, isso não quer dizer que as duas atividades não estejam interligadas.

Feito isso, tendo como base as análises já efetuadas, os acadêmicos decidem sob qual dimensão da produção escrita vão trabalhar: plano do texto, ou um elemento de textualização como a conexão, como a coesão nominal, ou como a coesão verbal, ou ainda as modalizações. A diretriz do trabalho vai depender do gênero que será ensinado e das dificuldades identificadas.

Já no caso do ensino da ortografia do francês, o objeto pode ser o plural do grupo nominal, ou os homófonos, ou outros elementos dessa natureza. Assim, diante dos diferentes aspectos da ortografia, o futuro professor seleciona um deles e produz um módulo com vários exercícios em progressão, trabalhando somente aquele elemento. Esses módulos terminam com uma situação de produção mais controlada, uma curta produção, isto é, uma produção chamada de simplificada. Esse processo permite conferir o efeito do módulo nas capacidades de linguagem dos alunos. De forma bastante resumida, é isso que temos feito na formação inicial do professor polivalente de ensino fundamental, na UNIGE.

No que diz respeito à formação continuada, outra parte de sua pergunta, os professores em atuação escolhem em quais dos cursos por nós oferecidos eles querem participar. Os profissionais se inscrevem e se houver número suficiente de inscritos, os cursos são ministrados. Esses podem ser sobre ortografia, produção de textos, leitura, escrita etc. Mas há também demandas de projetos de escolas e, nesses casos, somos convidados por uma instituição para dar uma formação bem específica, levando em conta as necessidades dos professores de cada instituição. Geralmente, partimos dos conhecimentos por eles denominados e, aos poucos, introduzimos abordagens mais específicas.

O trabalho com os gêneros textuais não é novo, pois vem sendo realizando desde os anos 90 , quando começamos a trabalhar com as sequências didáticas. Todavia, nos últimos anos, entraram em jogo outros parâmetros que não estavam sob nosso controle. São os parâmetros das instruções oficiais. Várias sequências didáticas que começam com a antiga primeira série e vão até a sexta série (hoje, sétimo ano) foram editadas nos livros didáticos S'Exprimer en français, em 2001. Esse era o material didático oficial para o ensino de produção oral e escrita em Genebra, na época. Em todas as escolas esse material foi comprado e estava sendo usado no ensino de francês. Também as provas cantonais (realizadas em cada Cantão de Genebra), que ocorrem no final da antiga segunda série, no final da quarta e no final da sexta, eram organizadas em função de gêneros textuais, tanto para o ensino da leitura quanto da produção escrita e oral. 
Então, após mais de 10 anos de publicação da coleção S’Exprimer en Français, a Direção do ensino primário optou por fazer nova escolha do material didático a ser usado nas escolas. Com a mudança, o material selecionado em 2015, e hoje em vigor nas escolas do cantão de Genebra (departamento/estado), mobiliza bem menos a noção de gênero. Com isso, enfrentamos um problema de formação, quer dizer: Como fazer para continuar a formar nossos futuros professores na perspectiva dos gêneros textuais? Pois, nós, formadores de professores, acreditamos que para ensinar a compreensão e a produção oral e escrita, é necessário passar pela noção de gênero de texto. É assim que pensamos e, atualmente, precisamos encontrar formas de superar essa contradição e estamos buscando solução à indagação: Como fazer quando os nossos livros didáticos de ensino do francês não caminham na mesma direção de nossas concepções teóricas e práticas?

Sei que esse desafio também acontece em outras realidades de ensino, inclusive no Brasil. Eu não fiz análise aprofundada do material didático usado nas escolas públicas brasileiras, mas pelo conhecimento que tenho de ambos os contextos, poderia dizer que, no momento, há mais coerência teórica lá do que aqui.

Para explicar melhor nossa realidade, o que houve foi que especialistas tanto do terrain - coordenadores pedagógicos, pessoas que trabalham nesses grupos mais ligados às Direções de ensino dos cantões francófonos, e também pesquisadores - fizeram uma avaliação de vários livros didáticos, todos franceses, os quais não tomam o gênero textual como base, uma vez que as sequências didáticas foram produzidas por pessoas daqui, de Genebra ou da Suíça francófona. A editora de S’Exprimer en Français é belga, mas foi a Comissão Romanda de Material de Ensino (COROME) que também o financiou. Enfim, é uma via de mão dupla entre essa comissão e a editora belga.

No entanto, os livros didáticos comprados a partir de 2010 vêm de editoras francesas. São livros concebidos para a escola francesa. A noção de gênero textual está muito pouco presente nas pesquisas francesas e ainda menos nas escolas da França. Resumindo, isso não quer dizer que a noção de gênero não apareça nesse material didático. Fala-se de gêneros, mas os princípios para definir um gênero são totalmente distintos dos da nossa equipe e, por vezes, é mais uma confrontação com a variedade de gêneros que é proposta do que propriamente um trabalho sistemático com os gêneros. $E$ me parece que essa abordagem é bastante semelhante ao método empregado em alguns livros didáticos que circulam na rede brasileira de ensino.

CW - Buscamos, hoje, no Brasil, formar um professor mediador, aquele que seleciona o objeto de ensino e, em conformidade com a estrutura sequencial e hierárquica das sequências de ensino, procura construir em parceria com o aluno o objeto ensinado, via aprendizagem. Você poderia traçar um perfil ideal do professor de línguas na perspectiva teórica da Didática das Línguas? As pesquisas voltadas ao processo de organização do trabalho do professor em sala de aula mostram a existência desse profissional atuando nas escolas de Genebra?

GSC - Esta é uma pergunta bastante difícil de responder. Vou tentar respondê-la com base em um perfil ideal na perspectiva teórica da Didática das Línguas, como pensamos no GRAFE, pois não se pode generalizar, uma vez que existem muitas outras perspectivas. Nesse contexto, para nós, o professor de língua deve ser um professor mediador. Mas o que ele vai mediar? A nosso ver, o famoso triângulo 
didático ${ }^{2}$ é um ponto de partida para responder essa pergunta, pois, com base nele se tem, acima de tudo, a preocupação com o objeto de ensino e como esse objeto é ensinado na sala de aula.

Para nosso grupo, a mediação do professor passa pelo objeto a ser ensinado e construímos esse enraizamento com base em Vygostki (2008). De modo bastante resumido, para mim, o professor ideal é aquele que consegue identificar com precisão um objeto de ensino e pensa sua mediação através desse objeto.

Mas no que se refere ao saber e às pesquisas voltadas ao trabalho dos professores em sala de aula, e se esses estudos mostram a existência de tal profissional atuando nas escolas de Genebra, posso dizer que os resultados do nosso livro Des objets enseignés (ver nas referências), relacionados ao nível do ensino médio, revelam essa tendência, no entanto, essa é uma questão muito complexa e difícil de delimitar, detalhar e exemplificar.

No livro, a expectativa que se tinha é que os professores partam de uma abordagem comunicativa de ensino dos objetos e não de uma ótica representacional da língua como tradução do pensamento. Nossos resultados situam o trabalho do professor em ambas as abordagens, num percentual de $50 \%$ para cada uma. A partir desse resultado, se pôde conferir qual foi o impacto da formação continuada de professores no trabalho com gêneros textuais por meio de sequências didáticas, pois também existem sequências didáticas na coleção S’Exprimer en Français voltadas para o ensino médio.

Observamos, então, que $50 \%$ dos professores se inspiram em uma abordagem comunicativa, que pode passar pelos gêneros de texto. Isso, porque nesses $50 \%$, poucos são os que vão ter uma abordagem sistemática organizada a partir do gênero textual escolhido para o trabalho. Foi possível ver que, de vez em quando, emergem, nesse trabalho, traços de uma perspectiva representacional, o que chamamos de "as camadas sedimentadas" de diferentes enfoques de ensino. Com relação ao objeto "produção de textos argumentativos" (tema da pesquisa), os outros 50\% dos professores situam-se na perspectiva representacional de tradução do pensamento, tendo como referência o tradicional ensino da dissertação e não a produção de um gênero de texto a partir de uma dada situação de comunicação.

Fica mais fácil responder sua questão com base nos resultados obtidos com a pesquisa, mas no que se refere ao papel do professor mediador, é difícil saber se os professores que assumiram uma abordagem comunicativa de fato construíram suas mediações com base no objeto ensinado. Uma boa resposta a essa pergunta exigiria que os dados coletados fossem revisitados para então conferir se, no caso desses professores, as mediações passam ou não pelo objeto de ensino.

CW - No contexto do ensino brasileiro, boa parte dos professores do ensino básico, em especial os de português, usa um livro didático em suas aulas. Nas escolas genebrinas, os professores de língua primeira costumam usar livro didático? Em sua formação, os futuros professores de francês recebem orientações para construir um material didático apropriado a cada ciclo?

GSC - Sim, na maior parte das ocasiões, aqui, no ensino de francês, parte-se de um livro didático. É o livro de base, e os futuros professores de francês recebem formação sobretudo para saber usá-lo e menos para construir o material didático. Temos dois veios nessa questão, vamos dizer assim.

Quando novos livros didáticos são adotados na escola pública, como o material que está em vigor no momento, o departamento de ensino propõe cursos de formação aos professores para o uso desses livros didáticos. Às vezes, os próprios autores são convidados para apresentar o material. Na verdade, é um

\footnotetext{
${ }^{2} \mathrm{O}$ triângulo didático foi desenvolvido pela teoria da transposição didática de Chevellard (1985), definido por três polos: professor, aluno e saber (ver Wittke, 2007).
} 
trabalho de apresentação da obra, das unidades que a constituem, e também esclarece como ele foi pensado.

Nós, professores da Universidade, procuramos fazer uma análise do material didático com nossos alunos, futuros professores. Para nós, o professor não é um mero aplicador. E não nos cansamos de repetir aos alunos que não estamos aqui para ensinar a eles como navegar ao longo do livro didático. Nosso trabalho consiste, sim, em ensinar como usar de modo crítico o material adotado. Então, usar um livro didático é saber fazer escolhas em função de objetivos de aprendizagem, é saber analisar justamente os exercícios, as atividades e tomar decisões com relação ao planejamento de suas aulas, à progressão curricular, tendo como ponto de partida e de chegada tais objetivos.

Nesse sentido, como já havia comentado na primeira pergunta, eu acho que o livro didático pode ser interessante quando o professor o usa de maneira crítica e como suporte para planejar e realizar sua aula. Nós já defendemos muitas vezes esse ponto de vista no Brasil, o Bernard Schneuwly, Joaquim Dolz e eu, pois entendemos que a função do professor não é a de criar material didático, mas de ensinar, de dar aulas. A profissão do professor consiste em saber apreciar e utilizar o material didático para alcançar os fins que pretende atingir com base nas orientações das instruções oficiais, dando conta do programa, ou melhor, do currículo.

Portanto, o professor deve se questionar quanto ao uso do livro didático que tem à disposição: "Como faço para atingir minhas metas de ensino?" E o professor pode e deve, é claro, também criar atividades e exercícios, porque ele tem, de certa maneira, um leque de possibilidades e, para nós, professores formadores, não é papel do professor criar absolutamente tudo. Nesse ponto temos algumas diferenças com relação a alguns pesquisadores brasileiros que vêm trabalhando com produção de material didático com o professor, principalmente durante sua formação na graduação.

Nós acreditamos que não é o papel do professor criar material. Para criar um material didático você tem muitas variáveis para controlar relacionadas à transposição didática do objeto a ser ensinado. Para isso, os autores de livros didáticos se apoiam em conhecimentos provenientes de outras esferas de saber para transpô-los e modelizá-los no âmbito da esfera escolar, em função dos objetivos de ensino de cada ciclo de aprendizagem, de cada série. É um trabalho complexo que leva em conta tanto esses objetivos como as capacidades reais e potenciais dos alunos a quem se destina tal material. Então, como o professor vai dar conta de ensinar e ao mesmo tempo preparar o material didático, levando em consideração todas as variáveis existentes? Parece-me muito difícil.

Eu digo isso por experiência porque tive a oportunidade de criar uma sequência didática sobre compreensão em leitura para a escola maternal e pude ver o quanto custa, o investimento e os conhecimentos que você precisa ter sobre o objeto a ensinar. Cabe lembrar que, quando usa um livro didático, o professor deve ser capaz de se adaptar à realidade da turma, pois precisa modificar e eliminar algumas atividades, já que, normalmente, não é possível trabalhar todos os exercícios e as atividades da maneira como são propostos no livro. Essa é a nossa batalha com os nossos futuros professores, no ensino de base, mas também com os professores em formação continuada: aprender a fazer seleções em função das capacidades de linguagem dos alunos e da progressão dessas capacidades. Toda a formação é baseada nesse princípio.

CW - Como você define o saber a ensinar e o saber para ensinar? Qual a relação dessas noções com o ensino e a aprendizagem de língua?

GSC - Os dois pesquisadores que mais desenvolveram essas noções foram os professores da FPSE 
Bernard Schneuwly e Rita Hofstetter ${ }^{3}$. Penso então que você terá uma resposta mais precisa com eles do que comigo. Eu não aprofundei muito essa distinção, pois trabalho mais com o objeto a ensinar do que com o objeto para ensinar.

Nessas condições, posso dizer apenas que o objeto a ensinar é aquele que o professor vai trabalhar na sala de aula e está nas instruções oficiais como, por exemplo, nos parâmetros curriculares nacionais de língua portuguesa. Um exemplo do objeto a ensinar é aquele tal qual foi transposto de uma área de conhecimento, como é o caso da Linguística, para as instruções oficiais de um dado nível escolar. Esse é o objeto a ensinar.

Podemos citar outro exemplo de objeto de ensino: os gêneros de texto, nos quais se incluem o artigo enciclopédico ou a receita de cozinha, dentre outros. É o conteúdo que está no trabalho prescrito, dizem alguns. Enfim, os Parâmetros Curriculares Nacionais (PCNs) orientam quais são os objetos a serem ensinados no ensino básico, no caso do Brasil.

CW - Em vários estudos do GRAFE, como é o caso do artigo "Les constructions de l'objet enseigné et les organisateurs du travail ensignant”, seu e de Schneuwly, publicado em 2007, vocês fazem referência à memória didática. Enfim, o que é memória didática e qual é sua relação com o processo de ensino e aprendizagem?

GSC - Realmente, a noção de memória didática foi o termo que menos desenvolvemos na pesquisa do GRAFE voltada ao trabalho do professor. O que foi possível mostrar nesse estudo é que a construção da memória didática está diretamente relacionada com os gestos didáticos fundamentais do ensino.

Nessa perspectiva, o primeiro gesto consiste em colocar em prática um dispositivo didático, o qual depende das instruções que são dadas, das reformulações de instruções que o professor pode ministrar, na medida em que apresenta e realiza sua tarefa. O segundo gesto diz respeito ao que chamamos de regulações, ou seja, os diversos tipos de regulações interna ou local, pelas quais o professor pode ajustar o processo de ensino e de aprendizagem. O terceiro remete às institucionalizações, aos momentos de "fixação do saber" e o quarto gesto refere-se à construção da memória didática.

Infelizmente, o pesquisador que era responsável por esse último gesto, pois temos o costume de dividir o trabalho na organização de nossas pesquisas, acabou não podendo continuar a trabalhar com o grupo. Em vista disso, nosso estudo ficou somente no nível da definição da construção da memória didática. Para nós, é tudo aquilo que antecipa o que vai ser feito ou se relaciona com o que já foi realizado em sala de aula.

Com nossa pesquisa, observamos que em todo o processo de ensino existe uma memória do que já foi feito e daquilo que ainda será realizado. Então, quando o professor diz: "Nós estamos trabalhando hoje com os organizadores textuais porque no texto que vamos escrever no final da sequência de atividades, vocês vão ser levados a usar esses organizadores para articular as diferentes partes do texto"; Ou fala: "Vocês se lembram que tínhamos trabalhado com as subordinadas relativas no ano passado? Hoje vamos utilizá-las no texto que vamos escrever"; esses são exemplos de dizeres do professor que compõem a memória didática, uma vez que eles ajudam a construí-la.

Todo processo de ensino envolve essa permanência dos objetos que é garantida pela memória didática. Ela ancora os objetos em uma progressão curricular que pode ser uma progressão do primeiro até o nono ano ou até o final do ensino médio, como também pode ser uma progressão curricular dentro de um

\footnotetext{
${ }^{3}$ Bernard Schneuwly é professor ordinário em Didática das Línguas na FPSE e um dos coordenadores do grupo GRAFE. Rita Hofstetter é professora ordinária da História da Educação na FPSE, na Universidade de Genebra e corresponsável pela equipe de pesquisa em História Social da Educação (ERHISE).
} 
mesmo ano ou ciclo. Assim, a construção da memória didática é a sistemática que garante justamente a coerência entre os objetos na escolaridade, tanto aqueles que já foram trabalhados quanto aqueles que ainda serão abordados.

CW - Um assunto bastante complexo e polêmico, independentemente da realidade escolar, é o processo de avaliação. A partir da leitura do artigo "Gêneros na escola: forma escolar e ensino-aprendizagem de língua", seu e de Schneuwly, publicado em 2010, pude perceber a referência a regulações internas e regulações pontuais nas sequências de ensino. Como funcionam esses dispositivos reguladores e qual sua relação com a avaliação formal no sistema escolar?

GSC - O GRAFE não desenvolveu estudo mais profundo sobre o tema da avaliação formal. Na seção de Ciências da Educação aqui na FPSE, temos uma equipe dirigida pela professora Lucie Mottier Lopez ${ }^{4}$, que é especialista em sistema de avaliação. Na nossa equipe, desenvolvemos mais a questão das regulações como gesto didático e também a função das grades de avaliação nas sequências didáticas.

Como já falei anteriormente, formulamos uma definição das regulações que não é necessariamente a noção que você vai encontrar, às vezes até com os mesmos termos, em outras pesquisas. Por exemplo, o que chamamos de regulação interna diz respeito a formas de regulação instrumentada, como as grades de avaliação que permitem que o aluno organize, planeje o texto em função das características do gênero em estudo. Essas regulações auxiliam o aluno no modo como vai organizar seu texto, principalmente considerando os aspectos que estão listados na grade, os quais são elementos referentes ao plano de texto, ao conteúdo temático, ao estilo etc. No entanto, outras ferramentas como um contraexemplo, ou um texto modelo, também constituem formas de regulação interna. Resumindo, as regulações internas são instrumentos que possibilitam uma autorregulação por parte do aluno, na construção do saber em foco.

Quanto às regulações denominadas locais, ou pontuais, essas são aquelas regulações que acontecem durante a construção do objeto, nas interações do professor com os alunos. Ela ocorre quando o aluno levanta a mão, faz uma pergunta, ou ainda quando o professor observa que há uma questão que precisa ser mais desenvolvida, melhor explicada. Nesse caso, o professor afasta-se do plano de sua aula para desenvolver mais essa questão. Ou ainda, quando há obstáculos na aprendizagem de um ou mais alunos e o professor precisa retomar o conteúdo em estudo, insistindo ou desenvolvendo mais o conteúdo em estudo.

No meu entender, os instrumentos de regulação e também os gestos didáticos fundamentais fazem parte da construção do objeto ensinado, e, nessa perspectiva, apresentam pouca relação com o processo de avaliação formal. Cabe destacar que as pesquisas do GRAFE não têm a avaliação formal como foco de investigação. Em nossos trabalhos, enfocamos a avaliação das capacidades dos alunos através de grades, que podem ser utilizadas nos momentos de apropriação das características dos gêneros pelos alunos, durante o estudo de uma sequência didática.

Essas mesmas grades também podem ser usadas no final da sequência quando o professor precisa dar uma nota, quando avalia a progressão do aluno do início ao final da sequência. Como se pode ver, trata-se de uma avaliação relativa dos aspectos do texto que foram contemplados, dos níveis de funcionamento linguístico que foram trabalhados e dominados ou não pelo aluno. Nossas investigações vão até esse ponto, pois não adentramos em reflexões sobre a avaliação formal propriamente dita, nem em suas

\footnotetext{
${ }^{4}$ Lucie Mottier Lopez é professora associada na FPSE e responsável pela equipe de pesquisa em Avaliação, regulação e diferenciação das aprendizagens nos sistemas de ensino (EReD). Ela também é corresponsável pelo "Réseau Maison des Petits", juntamente com Glaís Sales Cordeiro e Francia Leutenegger, sob o projeto "Enseignement de la lecture au cycle élémentaire et régulation des apprentissages des élèves" (RMDP, 2014-2018).
} 
diferenças com relação à avaliação formativa.

Nosso foco de interesse está no todo que constitui o processo de construção do objeto de ensino, tanto do ponto de vista do aluno, quanto da função mediadora do professor. No primeiro caso, o interesse está no processo de apropriação das dimensões do objeto pelo aluno, durante uma sequência de ensino; já no segundo, o interesse está em saber como esse profissional faz para mediatizar essa construção durante uma sequência, através das regulações internas e locais.

CW - Uma das grandes causas do fracasso escolar no ensino de língua materna nas escolas públicas brasileiras remete à falta de exercício constante de leitura. Considerando que você conhece tanto a realidade do ensino de língua no Brasil quanto na Suíça, gostaria que fizesse um paralelo entre os dois contextos, tendo o ensino da leitura como foco. Na sua opinião, como os Cursos de Letras podem e devem preparar os futuros professores de língua no que diz respeito ao ensino de leitura?

GSC - Inicio falando do trabalho realizado com a leitura no ensino obrigatório, o que, no Brasil, denominamos nível fundamental I e II. Tendo em vista o incentivo pelo gosto à leitura, acredito que os diferentes comportamentos do leitor devam ser levados em consideração no processo de leitura. Ou seja, o professor precisa se questionar sobre como é que a gente faz para ler, pois o gosto pela leitura vem desse domínio. Aqui na Suíça francófona (região de Genebra e arredores, onde o francês é a língua oficial), podemos ver que a leitura está bastante presente no cotidiano das salas de aula, mas, mesmo assim, ela ainda é pouco ensinada.

Com base na pesquisa sobre o ensino da leitura que a equipe GRAFE-LECT fez, coordenada pela professora Thérèse Thévenaz-Christen ${ }^{5}$, é possível notar que a leitura é ensinada, principalmente nas séries iniciais, nos segundo e terceiro anos. No entanto, à medida que o aluno vai adquirindo autonomia na competência leitora, a leitura deixa de ser ensinada e os professores começam a realizar questionários, cujas questões, na maioria das vezes, são literais, de natureza seletiva, buscando identificar informações presentes no texto, em detrimento de questões com caráter inferencial. Também se pôde observar que são em poucas salas de aula que o professor efetua um trabalho especificando o modo como se faz para relacionar as diferentes partes de um texto, ou mesmo para estabelecer relações entre as imagens e o texto em estudo.

No que diz respeito ao ensino dos diferentes gêneros de texto, com base na pesquisa supracitada, constatou-se a realização de um trabalho eminente com textos da ordem do narrar. Também foi observado que há poucas atividades com outros agrupamentos como os dos textos injuntivos (instrucionais), ou com textos da ordem do relatar, como é o caso das notícias, ou dos textos que transmitem conhecimentos, como os artigos enciclopédicos, por exemplo.

Em síntese, existe pouco trabalho em sala voltado a mostrar que não se lê textos de gêneros diferentes da mesma forma. Com essa perspectiva no ensino da leitura, alguns alunos pensam que quando você quer procurar uma informação num artigo enciclopédico, você precisa lê-lo do início ao fim quando, na realidade, os aprendizes poderiam se basear nos subtítulos para encontrar a informação que procuram. Isso mostra que o amplo processo do ensino da leitura é pouco desenvolvido ao longo da escolaridade. $E$ é justamente esse trabalho que possibilitaria mais prazer na leitura, porque o aluno se sentiria menos despreparado - uma vez que o prazer em ler vem, muitas vezes, do fato de o aluno não encontrar muitos obstáculos ao ler. Quando o aluno encontra dificuldade em decodificar, em identificar as informações

\footnotetext{
${ }^{5}$ Thérèrese Thénevaz-Christen é professora formadora e pesquisadora da UNIGE, hoje aposentada. Ela é membro do GRAFE e organizadora do livro: "La lecture au fil de l'école obligatoire. L'exemple genevois."
} 
essenciais no texto, ou não sabe como procurá-las, certamente, ele não sentirá prazer em ler.

Então, considerando a segunda parte de sua pergunta, sobre como os Cursos de Letras podem e devem preparar os futuros professoras de língua, vemos como essencial que formem esse profissional de modo que ele saiba lidar com todas essas questões e aprenda a ensinar a ler. Os Cursos deveriam preparar o futuro professor para lidar com tais problemáticas. Há também a questão do material didático, que ainda é insuficiente.

CW - Isso em termos de Brasil?

GSC - Em termos de Brasil, sim, mas também na realidade dos países francófonos. Temos uma variedade de livros didáticos - mas, em geral, eles trabalham muito com textos narrativos, como se os processos de leitura utilizados pelo leitor para ler tais textos fossem exatamente os mesmos mobilizados para ler textos de gêneros pertencentes a outros agrupamentos. Aliás, a noção de gênero de textos está ainda pouco presente no material didático e até mesmo nas reflexões de certos pesquisadores francófonos, cujos estudos estão voltados ao ensino de leitura. Isso mostra que ainda temos muito que avançar nesse domínio.

CW - Existem diferentes grupos de pesquisa na FPSE, em especial os do GRAFE, que se dedicam a estudar os processos de escrita e seus efeitos na formação docente e no ensino de língua. Você poderia descrever os resultados obtidos com os experimentos que seu grupo de pesquisa tem realizado sobre o processo de escrita?

GSC - Nosso grupo de pesquisa (GRAFE) efetuou uma produção bastante grande acerca do ensino da escrita até o início dos anos 2000, período em que produzimos uma gama variada de material didático. $\mathrm{Na}$ ocasião, a equipe realizou muitas pesquisas sobre ensino de escrita, tendo como base a noção de gênero textual e do dispositivo da sequência didática. No entanto, aos poucos, o olhar dos pesquisadores foi se direcionando a outra temática, que é a do trabalho do professor, pois aflorava o interesse em saber quais eram os efeitos dos materiais didáticos produzidos por nós nas práticas cotidianas dos professores.

Então, desde o momento em que os textos do GRAFE foram disponibilizados no Brasil, a partir de 2004, principalmente aqueles sobre o ensino de gêneros e sequências didáticas, a equipe não produziu novo material voltado ao ensino da produção escrita. Isso acabou acontecendo porque foi dado início à pesquisa sobre o trabalho do professor com o livro Des objets enseignés en classe de français, publicado em 2009. Esse material é resultado de uma pesquisa voltada para o trabalho do professor de final de ensino fundamental e início do médio, com relação ao ensino de textos argumentativos e da oração subordinada relativa.

Um bom exemplo dessa nova perspectiva de investigação é a pesquisa de Joaquim Dolz, já mencionada anteriormente, sobre o trabalho do professor nas instituições de formação. E depois de terminado o nosso estudo sobre os objetos ensinados em produção de textos/gramática em sala de aula, fizemos uma pesquisa acerca do trabalho com a leitura no ensino fundamental e início do médio no GRAFE-LECT. O resultado desse estudo foi publicado no livro La lecture enseignée au fil de l'école obligatoire. L'exemple genevois. Na sequência, o GRAFE-LITT começou uma pesquisa sobre ensino de literatura, estudo que ainda está em curso. 
Nesse contexto de pesquisa, comecei a me interessar mais pelo ensino da leitura nos anos iniciais da escolaridade, a partir do trabalho do GRAFE-LECT, em colaboração com as colegas Thérèse ThévenazChristen e Sandrine Aeby ${ }^{6}$. No presente momento, sou coordenadora, juntamente com Lucie Mottier Lopez e Francia Leutenegger, do projeto intitulado Réseau Maison de Petits. Trata-se de uma rede de escolas, que, atualmente, é composta por dois estabelecimentos, lembrando que um estabelecimento pode conter duas ou três escolas.

Hoje, estamos trabalhamos com três escolas e os professores manifestaram interesse em trabalhar com a leitura, mais especificamente, com a compreensão em leitura. Então, minhas pesquisas se reorientaram para a leitura e para a tentativa de ver como é que a noção de gênero de texto - que é pouco presente nos trabalhos de outros pesquisadores desse campo, poderia ser abordada nesses estudos. Sob tais condições, a escrita está presente em nossos trabalhos atuais, mas como um trampolim para a leitura, ou seja, em interação com a leitura, mas não é o objeto principal de nossa pesquisa.

CW - O ensino do oral é bastante recente na rede escolar brasileira e ainda pouco desenvolvido na formação do professor de língua portuguesa. Como a oralidade é trabalhada na formação do professor e também no ensino de francês nas escolas de Genebra?

GSC - A produção do texto oral aparece com a mesma importância dada ao ensino da leitura e da escrita nos parâmetros curriculares da Suíça francófona. Como já disse, até 2010, tínhamos parâmetros curriculares específicos para o ensino de Genebra. E nesses parâmetros curriculares, a noção de gênero de texto era fortemente apresentada com exemplos de gêneros orais, para compreensão em leitura e para a produção escrita, e isso para cada ação de linguagem (narrar, relatar, argumentar, etc.). Em síntese, era realmente bem detalhada e sistematizada.

No entanto, com os parâmetros que vigoram atualmente, o ensino continua focado na produção escrita, na produção oral, bem como na compreensão escrita e oral, fazendo referência à noção de gênero, mas agora de modo mais superficial. O problema é que nos livros didáticos propostos para o professor principalmente nos livros adotados nas séries iniciais, a tônica é a construção do sistema alfabético, com base na aprendizagem das correspondências fonema-grafema e de outros aspectos da ortografia. $E$, além disso, o professor precisa trabalhar com a produção escrita, com a compreensão e ainda com a produção oral. E, nessas condições, essa última fica em último plano e acaba sendo pouco trabalhada.

Cabe destacar que, nas provas cantonais anteriores à adoção dos novos livros didáticos, e anteriores ao novo plano de estudos romando (os parâmetros curriculares atuais na Suíça francófona), havia uma parte reservada à prática da compreensão e da produção oral. No entanto, atualmente, ainda que o ensino da produção oral apareça nas instruções oficiais, na prática cotidiana da sala de aula, ele é pouco realizado. Essa atividade acaba sendo minimizada, ou seja, se der tempo, trabalha-se com a compreensão e a produção oral, mas se não der tempo, paciência.

Já no que se refere ao modo como esse saber é construído na formação do professor, na UNIGE, temos cursos voltados especificamente ao ensino do oral, como faz o professor Joaquim Dolz. Eu também tenho um curso sobre o ensino do oral, voltado à escola maternal, mas, infelizmente, faz alguns anos que não o ministro. Isso aconteceu porque ofereci um novo curso sobre a aprendizagem da compreensão em leitura,

\footnotetext{
${ }^{6}$ Sandrine Aeby é professora da FPSE e membro do GRAFE. Ela também colaborou na pesquisa realizada pelo GRAFELECT, dirigida por Thérèse Thevenaz-Christen.
} 
também na escola maternal, e não foi possível dar conta dos dois cursos ao mesmo tempo.

Eu tinha a intenção de oferecer um curso em cada ano, pois assim, a cada ano uma turma teria uma formação específica sobre o ensino do oral ou da compreensão em leitura, no início da escolaridade. Mas, dadas as circunstâncias, ainda não foi possível colocar esse projeto em prática.

Vale lembrar que a Universidade de Genebra forma tanto professores que atuam no ensino fundamental quanto no médio, pois se trata de uma configuração diferente da formação de Letras no Brasil. A seção de Ciências da Educação, que pertence à Faculdade de Psicologia e Ciências da Educação (FPSE), é responsável pelos três primeiros anos da formação dos futuros professores do ensino fundamental, cuja formação é de professor polivalente, isto é, generalista. Já o último ano dessa formação é assumido pelo Instituto Universitário de Formação dos Professores (IUFE). Esse Instituto também forma os professores do ensino médio.

As modalidades de entrada nessa formação são diferentes do acesso às licenciaturas nas universidades brasileiras. Os estudantes que entram no curso de formação para o ensino fundamental acabaram de terminar o que chamamos de ensino médio. Esses alunos possuem um certificado de fim do ensino médio, porque não há Vestibular ou Enem em Genebra. É necessária uma formação completa de quatro anos para se tornar professor do ensino fundamental. Essa formação tem moldes similares a da Pedagogia, no Brasil, mas não é exatamente a mesma constituição, porque aqui, em Genebra, além das disciplinas voltadas para os aspectos transversais do ensino e da aprendizagem, os licenciandos também se formam em diversas didáticas disciplinares: do francês, da matemática, das ciências, de estudos sociais, etc., bem como em didática comparada.

Já no que diz respeito à formação dos professores que vão atuar no ensino médio, esses, para estarem aptos a ensinar o francês, devem ter uma licença em Letras. Isso significa que já fizeram os quatro anos de Letras e vão fazer mais três anos de formação específica para ensinar. Nesse caso, é uma formação em didática (mas também pedagógica sobre o ensino e a aprendizagem de modo geral), por exemplo, em didática do francês e de mais uma disciplina, História ou Geografia, ou Música. Esse é um público diferente, pois tais estudantes já obtiveram uma licença. O diploma que os professores do ensino fundamental e do médio recebem é dado pelo IUFE.

\section{Referências}

ANTUNES, I. Língua, texto e ensino: outra escola possível. São Paulo: Parábola, 2009.

CHEVALLARD, Y. La transposition didactique. Du savoir savant au savoir enseigné. Grenoble: La pensé sauvage, 1985.

CORDEIRO, G. S. Justifications des élèves et médiation de l'enseignante dans une tâche de compréhension en lecture d'un conte en maternelle, Repères, no 50, 2014, p. 157-176.

CORDEIRO, G. S. e SCHNEUWLY, B. Les constructions de l'objet enseigné et les organisateurs du travail enseignant. Recherche et Formation, no 96, 2007, p. 67-79.

DOLZ, J.; NOVERRAZ, M.; SCHNEUWLY, B. S'exprimer en français. Séquences didactiques pour l'oral et pour l'écrit. Notes méthodologiques. Volumes I, II, III, IV. Bruxelles: De Boeck \& Larcier. COROME, 2001.

GERALDI, J. W. O texto na sala de aula (Org.). São Paulo: Ática, 2006.

KOCH, I.V. e ELIAS, V. Ler e compreender os sentidos do texto. São Paulo: Contexto, 2010.

MEC/SEF Parâmetros Curriculares Nacionais (PCNs) - 3ำ e $4^{\circ}$ ciclos do ensino fundamental: Língua Portuguesa. Ministério da Educação e de Desportos Secretaria de Educação Fundamental, Brasília, 1998. 
Parâmetros Curriculares Nacionais do Ensino Médio - Linguagens, códigos e suas tecnologias. Brasília: Ministério da Educação, 1999.

ROJO, R (Org.). A prática de linguagem na sala de aula. Praticando os PCNs. São Paulo: Mercado Aberto, 2002.

SCNHNEUWLY, B.; CORDEIRO, G. S. Gêneros na escola: forma escolar ensino-aprendizagem de lingual. In: 30 olhares para o futuro. São Paulo: Escola da Vila-Centro de Formação, 2010, p. 91-97.

SCHNEUWLY, B. e DOLZ, J. Gêneros orais e escritos na escola. São Paulo: Mercado de Letras, 2004.

. Des objets enseignés en classe de français. Le travail de l'enseignant sur la rédaction de textes argumentatifs et sur la subordonnée relative. Rennes: Presses Universitaires de Rennes, 2009.

THÉVENAZ-CHRISTEN, T. (Orga.) La lecture enseignée au fil de l'école obrigatoire. L'exemple genevois. Namur: Presses Universitaires de Namur, 2014.

TRAVAGLIA, L. C. Gramática e interação: uma proposta para o ensino de gramática. São Paulo: Cortez, 2003.

. Tipologia textual, ensino de gramática e o livro didático. In: HENRIQUES, C. \& SIMÕES, D. (Orgs.). Língua e cidadania: novas perspectivas para o ensino. Rio de Janeiro: Ed. Europa, 2004.

VYGOSTKI, L. S. Pensamento e linguagem. São Paulo: Martins Fontes, 2008.

WITTKE, C. I. Ensino de língua materna: PCNs, Gramática e Discurso. Santa Cruz do Sul: EDUNISC, 2007.

O efeito discursivo da descrição escolar em manuais de língua estrangeira. Pelotas: Editora e Gráfica Universitária da Universidade Federal de Pelotas, 2011.

Ensino de língua e formação docente. Reflexão teórica e diálogo com professores. Saarbrücken, Deutschland: Novas Edições Acadêmicas - Verlang Editora, 2015. 